\title{
A Framework for Capacity Building in Adult and Workforce Education Programming
}

\author{
Elizabeth A. Roumell, Texas A\&M University \\ Corina Todoran, Loyola University New Orleans \\ Florin D. Salajan, North Dakota State University
}

\begin{abstract}
Recent Workforce Innovation and Opportunity Act legislation in the United States has initiated increasingly complex and multi-tiered systems for program implementation in the adult learning, career training, and workforce development sectors. The paper presents a conceptual framework to assist in understanding capacity building for implementation of adult and workforce education programming. The framework synthesizes a number of policy models, dimensions, and definitions for program delivery and capacity building. A capacity building framework can be applied for conducting policy analysis, needs assessment, and evaluation to underscore how the execution of ambitious policy initiatives and the sustained use of effective practices in communities and institutions, is more likely to be effective if the implementation process begins with a clear understanding of the program model and policies themselves. It also assists in building an active investment in and intentional cultivation of systemic capacity for implementation. Efforts at executing new initiatives without attending to system-level development and scaffolding support structures are prone to ineffective realization and poor program sustainability.
\end{abstract}

Keywords: adult education, workforce education, WIOA, policy analysis, Career Pathways, implementation, capacity building

The 2014 Workforce Innovation and Opportunity Act (WIOA) legislation carries with it many implications for the trajectory of adult and workforce education (AWE) in the United States (Brown \& Holcomb, 2018). The intent of the progressive development of federal legislation and the national Career Pathways (CP) model has been to integrate workforce development and training with adult learning and literacy programs through partnerships and by streamlining policy aims and outcomes. The impact of the WIOA and CP models on state-level workforce education policy, adult learning program implementation, and adult education practice in general cannot be understated (Uvin, 2018). The continued alignment of reporting and assessment requirements has also assigned additional responsibilities to program directors and adult 
educators requiring new professional skillsets and knowledge for effective program and curriculum implementation. However, such AWE mandates and requirements often have not been matched with the additional resources and professional development necessary for effectively carrying them out (Ladinsky, 2017).

Given the complexity of the AWE policy arena, where multiple federal agencies and statelevel agencies are involved in developing and implementing educational policy for adult learners, and that the CP model is currently guiding a significant amount of program reform, we argue that a clear capacity building framework is necessary for conducting strategic policy and implementation analyses. A clear framework can be an important tool for both understanding AWE policy, as well as for identifying avenues of action and influence in practice and within the policy arena. We aim to accomplish two things in this article. First, we present a policy analysis framework centered on the notion of capacity building that can be used as a tool for making better sense of policy and its implementation. Second, we argue that a capacity building framework is critical when it comes to implementing adult-centered education programming in our current policy climate and context. We acknowledge that AWE programming varies dramatically from state to state, so our intent in presenting this framework is to offer a point of departure for more intentional policy analysis and to suggest a capacity building approach toward improved delivery of AWE programming.

To accomplish this, we offer an historical overview of the development of the current AWE legislation and CP model to provide context. Then, we articulate a conceptual framework for AWE policy implementation that synthesizes conceptual models, policy domains, and definitions for capacity building. We follow the presentation of the capacity-building framework by presenting an example case of an initiative implemented in Texas to illustrate the importance of capacity building for implementation. Finally, we argue that efforts to carry out AWE initiatives and programming without attending to system-level development and support structures may result in both ineffective implementation and poor program maintainability.

\section{Policy Pathways: How We Got Here}

In order to know where we are going, it helps to know where we have been. A brief sketch of more recent AWE policy developments helps contextualize the current policyscape and present why we believe a capacity-building policy analysis framework is critical for educational programming and the carrying out of new initiatives. In the late 1990s, U.S. legislators, the U.S. Department of Education (ED), and adult education leaders communicated a need to pair adult literacy programs with postsecondary education and job training. Policy makers posited that an expanded scope was necessary in order for adult learners to not only improve literacy skills, but also obtain postsecondary education, work skills certification, and other industry recognized credentials (ED, 2013). Consequently, the 1998 Workforce Investment Act (WIA) began an incremental reformation of the diversified and complex AWE delivery system. The stated WIA (1998) purpose was "To consolidate, coordinate, and improve employment, training, literacy, and vocational rehabilitation programs in the United States." The integration of adult education within a workforce framework reflected a growing emphasis on linking literacy, education, and employment services (Uvin, 2018). Similarly, 
the U.S. Department of Labor (DOL) replaced the 1982 Job Training and Partnership Act, and statewide and local workforce investment systems were established. The initiative aimed to provide workforce investment activities, through statewide and local workforce investment systems, to improve the quality of the workforce, reduce welfare dependency, and enhance national productivity and competitiveness (ED, 2013). From a federal policy standpoint, this is where adult education and workforce training programs were initially wed together.

U.S. federal legislation provided states the opportunity to submit a single unified plan that would address coordination of activities for employment and training, adult basic education, and Perkins Career and Technical Education programs. Of nearly equal importance was the mandate that adult education programs partner with the local workforce development systems. WIA legislation also required the creation of a performance accountability system to assess the effectiveness of AWE programs, holding states accountable to the ED in a systematic way (Roumell, Salajan, \& Todoran, 2020). The layers of the AWE system were gradually being formalized through these legislative initiatives, creating a structure connecting local programming to regions, to the state, and finally to the federal level. This formalization carries with it myriad implications for programs and practitioners alike (Brown \& Holcomb, 2018).

The federal government further integrated the AWE infrastructure through the outlined CP model which initially appeared in the 2006 Carl D. Perkins Career and Technical Education Act (Perkins Act), serving as the precursor of the policy template for the 2014 Workforce Innovation and Opportunity Act (WIOA). In 2007, an Interagency Adult Education Working Group was created within the ED and ordered to identify and review federal programs related to adult education with the purpose of improving the integration of the systems for the delivery of AWE programming. In April 2012, a joint letter was issued by the U.S. Departments of Education, Labor, and Health and Human Services to form a federal partnership articulating a joint commitment in promoting the use of "career pathways" to strengthen the workforce development system through alignment and improvement of employment, training, and education programs (DOL, 2012). This multiagency commitment to coordinate programming across several areas further accelerated reform in AWE policy and programming.

WIOA (2014) consolidated job-training programs under 1998 WIA and further streamlined the process. WIOA (2014) ushered in increased reporting and accountability requirements, the alignment of content and standards between various levels and kind of education, the requirement for workforce development and education partnerships, and diversified stakeholders and providers in both the private and non-profit sectors. The intent of the reform was to establish more uniformity, increase oversight for quality, and improve the effectiveness of AWE for both individuals and for employers who need skilled workers to compete (Uvin, 2018). Needless to say, while most AWE programming across the spectrum is still primarily the responsibility of individual states and programming is locally driven, the current CP model and WIOA federal requirements for funding continue to proliferate and oblige greater centralization of standards, accountability, evidence-based programming and practices, and enhance overall federal oversight (Roumell, Salajan, \& Todoran, 2019). These policy initiatives at the federal level, and the multi-agency approach to the CP model, has 
established an unprecedented effort at reforming educational programming for adults at all levels and far reaching implications for practice (Brown \& Holcomb, 2018).

\section{A Framework to Map Where We are Going}

With the renewed (2016) commitment to the CP working group, the six key elements for developing comprehensive CP systems that were included in the April 2012 Joint Letter (DOL, 2012) have been carried forward and are meant to provide a model for states to follow in building an infrastructure for integrated CP systems. The six main elements that comprise the CP model include: building cross-agency partnerships and clarifying roles; identifying industry sectors and engaging employers in business and industry; designing education and training programs; identifying funding needs and sources for implementation; aligning policies and programs between federal, state, and community agencies; and measuring system change and performance (DOL, 2016).

The driving impetus behind this strategic process model and the federal legislation is to develop infrastructure and build systems that have improved capacity for implementing high impact educational programming throughout the ongoing, outlined structured strategic CP process (Mortrude, 2017). Recent research has begun to highlight the need for continued capacity building for implementing meaningful programs and interventions in the field of adult education (Cincinnato, De Wever, Van Keer, \& Valcke, 2016; Ladinsky, 2017; McIntyre, 2008; Morgan, 2016). The model bears a striking resemblance to other federal-level capacity building initiatives since the 1990s in areas like community development and health education programming (Lauzon, 2013). For example, Lauzon (2013) describes the evolution of a capacity building approach in agricultural extension, which emerged in the 1980s and proliferated throughout the 1990s and into the new millennium. In his description, he argues that capacity development requires more than efforts focused on strengthening the economy, emphasizing an approach that requires communities and all levels of stakeholders to become more involved in the planning and implementation of their own policy initiatives and programming. Lauzon highlights the value of stakeholder participation and building capabilities at all levels of implementation.

Much can be learned from capacity development initiatives and other educational and social services programming that have been following capacity building models (similar to the new WIOA framework) for years. Scholars in the area of implementation science have also been developing frameworks for improving the implementation and scaling of evidence-based programming across a variety of disciplines. Horner, Sugai, and Fixsen (2017) point out that the upscaling of evidence-based initiatives depends on a number of factors, and that, "Too often effective practices are proposed without attention to the breadth of systems variables and implementation tools needed to facilitate adoption, reliable use, and sustainability over time, and generalization across settings, and staff” (p. 26).

Struyk, Damon, and Haddaway (2011) offer a basic definition of capacity building for the purpose of evaluation: "Capacity building consists of activities designed to increase the competence and effectiveness of individuals and organizations" (p. 50). Morgan's (2006) description of capacity building refers to "collective abilities," implying that it is the aggregation of skills, knowledge and abilities that enable a system to perform, deliver value, build collaborations, and to continue to 
renew itself. The United Nations Development Program (UNDP) defines capacity building as,

The process through which individuals, organizations, and societies obtain and maintain the capabilities to set and achieve their own development objectives over time. Capacity development is not a one-off intervention but an iterative process of design-application-learning-adjustment... Approaching capacity development through this process lens makes for a rigorous and systematic way of supporting it... It also helps promote a common frame of reference for a programmatic response for capacity development. (2008, p. 4)

In order to support capacity building, a framework is helpful in identifying what key capacities already exist, and what additional capacities need to be further developed to reach the outlined program objectives more effectively. In developing and applying a framework for examining current policies and implementation processes, we are better able to compare current existing capacities to the desired capacities necessary for success. A framework for analysis can help generate a more nuanced understanding of how to optimize existing capacities, what capacities are still needed for successful implementation, and how to develop strategies for strengthening overall system and organizational capacity (UNDP, 2008).

One of the stated overarching WIOA aims is the alignment of policies, standards, and goals between federal agencies, as well as with state and local level agencies toward the improvement of infrastructure and organizational capacity to provide evidence-based initiatives (EBIs) and programming that are in alignment with federal and state legislation. The CP process model, however, does not more specifically elaborate on the critical elements and planning practices for building sustainability and maintainability, which we argue are critical components in building infrastructure and community capacity for implementing CP evidence-based strategies and programming (Foman et al., 2013).

Here, we briefly introduce and articulate seven key elements within a capacity-building framework that can be leveraged for needs assessment, program implementation processes, evaluation design, or policy analysis (at the community, or state level) (UNDP, 2008). The model is a synthesis of the Council for Adult and Experiential Learning (CAEL, 2008) policy-analysis framework, Roumell's (2017) community-capacity-building dimensions, and the Plested, Edwards, and Jumper-Thurman (2006) community-readiness model employed in community public health programming. The additional policy dimension of cultural congruence addresses the concerns about culturespecific interventions as outlined by Nastasi and Hitchcock (2016).

The CAEL (2008) Adult Learning Policy Review Framework included the following nine areas for policy analysis: governance, strategic plans, performance measures, state agency programs, postsecondary education programs, finance, student financial assistance, consumer information, and stakeholder involvement. In the framework outlined here, the components of capacity building closely mirror the key elements of the CAEL framework, but we also integrated elements that are in alignment with the Federal CP model, as well as elements that help in assessing a system's capacity for the strategic implementation process. This framework includes perspectives regarding contextual implementation considerations, as well as elements to determine the system's capacity to carry out changes in policy and to implement new policies and programming.

The framework we present adds to Horner et al.'s (2017) more formal definition of community/ organizational implementation capacity, which 
they define as the ability to address the following elements in program implementation:

1. Formal mission or policies that indicate the primary objectives for skills enhancement and individual development.

2. Human resources procedures that recruit and hire individuals with documented competence in multi-tiered systems implementation and orient all new personnel to the aspects of multi-systemic support, and establish accountability measures.

3. Data systems that allow the leadership team, vital administrators, and implementing staff to assess the progress and quality program implementation.
4. Training and coaching capacity that allows improved adoption and consistent use of policies and programs.

5. Technical expertise in the systemic support that assist key personnel in implementing multi-tiered practices with the precision and sophistication needed for the establishment and operation of sustainable programming.

6. Relevant examples of policy and program implementation that are used to develop processes for documenting the feasibility and demonstrating the value of new practices. (Horner et al., 2017, adaptation of their list on page 32 ).

The success of CP and AWE programming will hinge on the ability of states, regions and

\section{Table 1: Adult and Workforce Education Capacity Building Analysis Framework}

CAPACITY BUILDING DIMENSION

Framing and Community Climate

Leadership \& Stakeholders

\section{QUESTIONS TO GUIDE CB ANALYSIS}

- What are the prevailing attitudes of the community regarding the issue? Are stakeholders and the community interested and willing to take initiative and ownership of issue?

- How knowledgeable are the stakeholders and community about key factors that influence the issue the intervention is intended to address?

- How knowledgeable are the stakeholders and community about current local efforts to address the issues, their (non)effectiveness? (i.e. current efforts, programs, and policies to address identified issue)

- Is there leadership buy-in to the proposed initiative, as well as among the varying levels of stakeholders?

- Are the necessary social-cognitive resources (potentials-beliefs and values) available to help those involved in implementation to carry out the initiative?

- Are those involved in implementation, individually and collectively, ready and willing to implement the intervention (contributions) both cognitively (e.g. sense making, reflexive monitoring) and behaviorally (collective action/learning)? 


\section{Table 1: Adult and Workforce Education Capacity Building Analysis Framework (continued)}

\section{CAPACITY BUILDING DIMENSION}

Evaluation and Data Use

Planning \& Maintainability

Evidence-Based Practices

\section{QUESTIONS TO GUIDE CB ANALYSIS}

- Are those involved in implementation familiar with conducting evaluation through regular collection and use of data to continually guide decisionmaking?

- Which data are needed, and what data are available? How are data currently used in planning? How are data collected, analyzed, and reported for strategic planning purposes?

- To what extent have the intended outcomes of the initiative been achieved (program impact)? What were both the intended and unintended outcomes?

- To what extent have the somewhat immediate outcomes (proximal outcomes) been achieved (community level and participant level data)?

- To what extent have the more indirect and long-term (distal outcomes) been achieved (state or broader level measures)?

- How well are the outcome measures suited to the setting (consequential validity)? What are the real consequences of poorly aligned measurement? (poor social validity can undermine program effectiveness)

- Are the decision-making groups actively collaborating (including planning groups, advisory boards, and all agencies and stakeholders) and is regular cross-system coordinated planning occurring to ensure long-term sustainability? Are any key groups being left out or overlooked?

- Is there coordinated decision-making between government, funding agencies, private sector, not-for-profit, or other sectors?

- To what extent will the initiative be able to continue without external conditional support (grants) and able to maintain current efforts long-term (maintainability)?

- Are local resources available to support ongoing efforts, including people, expertise, time, money, space, information/data, media/dissemination?

- What are the social-structural resources (infrastructure/capacity) available for implementation (i.e. social norms, roles, materials, and cognitive resources within the system)?

- Is the importance evidence-based practices recognized, encouraged, and consistently performed at all levels?

- Do individuals have access to the necessary training and professional development for evidence-based practices?

- To what extent are the programs/policies being implemented as designed (program integrity - fidelity/adherence) paying attention not only to surface level but also deep structural level elements? 


\section{Table 1: Adult and Workforce Education Capacity Building Analysis Framework (continued)}

\begin{tabular}{|c|c|}
\hline CAPACITY BUILDING DIMENSION & QUESTIONS TO GUIDE CB ANALYSIS \\
\hline Cultural Competence \& Congruence & $\begin{array}{l}\text { - Is the importance of audience appropriate practices that are congruent } \\
\text { with the needs of the participants and needs of the community recognized, } \\
\text { encouraged, and promoted at all levels? } \\
\text { - Are the perspectives of stakeholders regarding the feasibility, importance, } \\
\text { probability of success in alignment and congruent (program acceptability) } \\
\text { with shared worldviews of the communities and participating demographic } \\
\text { groups? }\end{array}$ \\
\hline Implementer Capabilities & $\begin{array}{l}\text { - What is the likelihood that those who are responsible for } \\
\text { implementation can operationalize the intervention based on } \\
\text { feasibility and actual contextual fit (capability)? } \\
\text { - Do the people who have to execute the initiative/policies have the } \\
\text { necessary knowledge, attitudes, and skills to successfully implement } \\
\text { the program with integrity, and to adapt to program needs in a way } \\
\text { that is responsive to and meets contextual and cultural needs of the } \\
\text { recipients? } \\
\text { - Are there sufficient, well-trained personnel, resources, and } \\
\text { encouragement of multi-disciplinary training? What is the context of } \\
\text { the stakeholders and qualified specialists responsible for carrying out } \\
\text { the initiative? }\end{array}$ \\
\hline
\end{tabular}

Note: Derived from Plested, Edwards, \& Jumper-Thurman (2006); Roumell (2017); and Nastasi \& Hitchcock (2016)

providers to build systemic capacity for interorganizational learning (Mariotti, 2012) and knowledge and process management. Examining the seven categories within the framework can help identify needed areas of capacity building for implementation. The framework provides concepts and language to help program leadership develop capacity-building objectives and better communicate the professional and capacity development needs to implementation partners, stakeholders, and policy makers. Developing systemic capacity for implementation requires knowledge about what sources and kinds of data are available, an understanding of how various kinds of data can be used as indicators for the desired outcomes, personnel who are capable of performing the appropriate data collection, maintenance, and analyses, and leadership who can interpret and effectively use the information to further guide the implementation process (Horner et al., 2017).

The requirements of the new WIOA and CP initiatives demand greater process management and data use capabilities at all levels (Roumell et al., 2019). These added programming requirements put further strains on programs 
and providers who are already under-staffed and under-resourced. Several recent studies indicate that these areas of capacity building may be major barriers to CP implementation, due to lack of resources, high staff turnover rates, and lack of continuity at all levels (Couch, Ross, \& Vavrek, 2018; McDonnell \& Sricone, 2018; Ladinsky, 2017; Prins \& Clymer, 2018; Smith, Dillahunt-Aspillaga, \& Kenney, 2017). Using such a framework can help leadership and providers identify key areas for professional development, but also help craft the necessary language and baseline assessments to more successfully argue for necessary implementation resources.

Building community and state capacity for systematic data use and evaluation cannot be overemphasized, as the entire federal WIOA and CP implementation model hinges on how well organizations and agencies will be able to use information throughout the entire implementation process (Ladinsky, 2017). Couch et al.'s (2018) findings from their national program review of I-BEST programs emphasized that programs where data collection and evaluation were built into their program implementation were better able to adapt and measure implementation, offering evidence of the crucial role of data and evaluation management in filling important program knowledge gaps. They submit that,

One potential opportunity for individual states and localities interested in exploring innovative methods for workforce development is to similarly conduct convincing analyses that can help understand what works and why. Data-driven pilot programs offer an opportunity for understanding the mechanisms that help enhance workforce outcomes and increase program retention. (Couch et al., 2018, p. 119)

The capacity of the leadership to effectively utilize data, but also the community/ organization's capacity to generate, collect, maintain, and contribute useful data throughout the process are instrumental. This is particularly critical for $\mathrm{CP}$, as the efforts are multi-agency collaborations and are dependent on establishing partnerships that require the integration of multiple goals and outcomes. All things considered, Jacobson (2017) foresees substantial challenges when it comes to adopting and implementing common standards and reporting, stating that "states will need to build and sustain robust professional development systems to support their implementation in practice" (p. 23).

\section{Learning From Those Who Have Gone Before Us}

As a brief case in point, we will discuss the idea of capacity building and the need for a more nuanced understanding of policy implementation as was experienced within the context of the State of Texas regarding new laws impacting developmental education (DE). While Developmental Education primarily lies within the purview of higher education and the remediation of incoming students, the specialization area has already undergone similar shifts in policy initiatives, standards alignment, changes in assessment practices, and increased data reporting requirements. Much can be learned from the experiences of these educators in their similar plight, without making a negative case or example of any of our current CP programs. That is to say, we can examine a related policy implementation nettle, and learn valuable lessons from those who have implemented such systemwide changes in the past.

Womack's (2018) policy study investigated the planning, implementation, and assessment of the Texas Success Initiative (TSI) which inculcated sweeping changes in DE and was carried out in postsecondary Texas institutions starting in 2010. The purpose of the TSI was to 
improve the academic success of underprepared students as they entered postsecondary education institutions across the state (Texas Higher Education Coordinating Board [THECB], 2014). The initiative represented a sweeping legislative effort at addressing the low completion rate of transitioning college students in Texas through the promotion of basic remediation and developmental education programming in English reading and writing and math courses.

The definition of DE put forth by the National Association for Developmental Education (NADE, 2017) reads, "Developmental education is a comprehensive process that focuses on the intellectual, social, and emotional growth and development of all students. Developmental education includes, but is not limited to, tutoring, personal/career counseling, academic advisement, and coursework" (n.p.). DE offers remediation for students who are moving from adult basic education to GED, to further postsecondary education programming. The TSI established score requirements on statewide standard Texas assessments for college entrance and established uniform cut-off scores for various levels of DE to be used state-wide. In this sense, the aim of TSI was to establish more consistent entrance and test score requirements across postsecondary institutions, and more uniformity in the DE provisions to improve academic success rates and transfer of DE units-aims not dissimilar to WIOA legislation and CP initiatives.

For brevity, we will use some of the capacity building concepts to summarize Womack's (2018) analysis of the TSI legislation and implementation process. First, the purpose of the policy was to formalize and create common measures and expectations across systems in the area of DE. The primary objective was to improve the basic academic skills individuals need to be successful in completing postsecondary programs of study. While the population indicated by the policy was limited to students within a defined range of assessment scoring and academic need (which previously had been different between institutions and from system to system), nearly all postsecondary and higher education institutions were implicated in the execution of the new policy. Even though the policy changes seemed straightforward and were intended to affect a defined subset of students, the extent of the required systemic changes were, in actuality, far more extensive than anticipated. Even though the intent of the policy was to provide more clarity in academic expectations, uniformity between educational institutions statewide, and to facilitate DE and smooth transitions for learners into their postsecondary education to improve success rates, Womack's (2018) study clearly demonstrated that the state system and the affected postsecondary institutions were not adequately prepared to carry out the new requirements. The policy intent was clear, but the pathway for integrating the new requirements and implementing the policy was underdeveloped. We have also recently identified similar observations and critiques in the literature pertaining to the WIOA and CP initiatives (Cushing, Therriault, \& English, 2017).

While the new law may have seemed reasonable from a policymaker's standpoint, the changes affected many of the basic operations within educational institutions, and the impact of the requirements and the intricacies of making major systemic adjustments were underestimated. Implementation concerns included the processes related to the human resources procedures within institutions (admissions, enrollment, staffing, curriculum), and the competencies and ability of staff responsible for the changes across the multi-tiered systems. In this particular 
case, little was done to prepare and orient all personnel and educators to the relevant aspects of the policy or build multi-systemic support that would be needed to carry out the TSI measures. The new requirements were disseminated, but a blueprint for successful implementation was not provided, nor were a support structure or technical assistance developed to help institutions align their own policies, assessments, admissions procedures, student advising, or DE curriculum. Each institution was left to their own devices in figuring out how to integrate the new requirements into their operational structure, and little guidance was provided in terms of how to transition from their individual institution procedures to the new state requirements (Womack, 2018).

The excitement from the supporters of the TSI agenda that spurred the legislation had strong public support, but the initiative did not seem to garner similar levels of support from program directors or practitioners (Womack, 2018). The new standardized tests that were utilized for admission and for placement, for instance, had not been validated and were not viewed favorably by practitioners. The policy recommendations included some strategies for change that had been piloted elsewhere, but were not based on replications or longitudinal data, and so many institutions did not consider the approaches to be evidence-based. For example, acceleration programs and classes to shorten adult students' time-to-graduation were implemented, even though the empirical evidence for their effectiveness was highly contested. Institutions, providers, and educators also received minimal training or guidance on how they were supposed to integrate the new programming.

Little structure was provided in terms of data systems and guidance to allow administrators and implementing staff to assess the progress of how well institutions were doing in carrying out the new DE requirements. Training and coaching were also not provided for those who were responsible for making the necessary adjustments, diminishing their capacity to successfully adopt the new policies in a way that would significantly impact student success. Therefore, the process was largely left up to the DE practitioners to experiment with implementation of the many dimensions of the TSI legislation, as well as to find ways to assess the outcomes and share what they were learning with their colleagues across the state. Womak (2018) argued that an execution strategy was left largely on the shoulders of the existing DE practitioners. Overall, the systemic support necessary in developing the technical expertise and assisting key personnel in implementing multi-tiered practices with the precision needed had not been adequately addressed within the various systems and institutions.

Hoogervorst (2011) asserts that the common failures of education initiatives are most often the result of inadequate strategy execution. In the Texas case, the state tried to carry out several major changes simultaneously but did not fully consider the complexity of the systems that would have to carry out the changes. This particular initiative involved the system of higher education in the state of Texas, which includes 105 institutions, 50 of which are community colleges with multiple campuses (THECB, 2014). Additionally, the implementing agents were comprised of the academic and student services leadership within the structure of each educational institution. Despite the magnitude of change required by the statute, the legislature enacted the TSI without financial support to meet the additional administrative and staffing 
needs required for fully implementing the many requirements of the statute (Womack, 2018). Similar concerns have been noted regarding WIOA and CP implementation (Jacobson, 2017; Prins \& Clymer, 2018; Smith et al., 2017).

The alignment of authority and system accountability was also a concern. In this case, technically, the TSI is the responsibility of the THECB, but the initiative falls under the purview the Director of Adult and Developmental Education (DADE). This also indicated possible misalignment of authority and responsibility, where DADE actually had no authority to affect the DE decisions, and was only able to furnish explanations, interpretations, and to provide encouragement and limited resources for implementation, and could not compel institutions or practitioners to perform specific actions. As a result, most institutions responded by making bare minimum adjustments merely to be in compliance with the new law, but little more, rendering the overall purpose of the legislation fairly impotent. Most DE faculty and support staff have continued to provide the same services and curriculum as before, meaning that the new requirements aimed at improving $\mathrm{DE}$ services have actually had limited potential for improving remediation classes or impacting the overall success rates of adult learners in any meaningful way. Similar questions persist regarding CP implementation, and whether various aspects (career training or other support services) have been merely "tacked on" to already present programs, or only superficially addressed in programs (McDonnell \& Soricone, 2018; Smith et al., 2017).

The TSI legislation was not developed in consultation with DE experts, and relevant exemplars of evidence-based initiatives were not used as foundational examples for the design and implementation of the DE initiatives. The new laws were well intended, and the notion of providing some uniformity and improving transitions and flow for students in the wider Texas system of postsecondary education was not lost on the DE practitioners. Nevertheless, the lack of attention to systemic implementation capacity and the magnitude of institutional change required to implement the policies diminished the policy focus: focus on getting students into credit level courses; focus on getting students onto pathways where they can be successful; focus on student progress; focus on a variety of education programs as good career options; and focus on transferable credentials. This may be a case where well-intended policy may have inadvertently over-burdened the personnel implementing the changes, detracting from their overall ability to successfully serve their target population.

Many of the aims and purposes of the TSI were very similar to those of WIOA and the CP initiatives. The TSI legislation and the complexity of the Texas postsecondary education systems bear some resemblance to the federal-level CP efforts with similar policy volition and complexity of implementation. The Texas system is complex, and mirrors AWE policies in that multiple agencies and institutions are involved in decision-making and implementation. The TSI is a case study, a microcosm perhaps, of what WIOA and CP implementation may look like. The example of TSI is a relevant illustration of the importance of a more nuanced analysis of educational policy initiatives and system implementation capacity. As states, systems, and institutions continue to implement WIOA mandates and the CP model, they will need to address similar implementation barriers as those faced in Texas. In fact, Jacobson (2017) recently articulated similar concerns about the complexity of WIOA and CP, specifically 
noting issues related to: curriculum and testing standards; disconnections between local and state level planning; concerns about of alignment of authority and oversight (i.e. workforce boards' authority over educational institutions and processes); alignment of metrics and measurement processes; unintended causes of employment driven metrics; and finally issues related to resources and capacity to successfully implement the initiatives. Somehow, it feels as though we've already read this story before. As AWE policy continues to shift within the CP framework, it is in the best interest of practitioners, directors, and institutions to pursue and promote more systematic, structured and cogent policy analyses to identify and more effectively communicate capacity development needs.

\section{Discussion}

The TSI is instructive, and Womak's (2018) implementation study offers an example of the kind of policy and implementation analysis such a capacity-building framework can engender. A framework for analyzing AWE initiatives can provide a structure for identifying and understanding implementation dynamics and emphasis, as well as a departure point to develop interview and/or survey protocol for talking to stakeholders and policy makers. A capacitybuilding conceptual framework can also be used to help structure assessments of infrastructure and implementation analyses at institutional, community, or the state levels. Not only can a capacity-development framework be used to guide data collection and building assessment tools, but it can also be leveraged to identify possible data sources and indicators to for the purpose of evaluation (Ampelrese, 2016; Struyk, Damon, \& Haddaway, 2011; UNDP, 2008). These practical applications give practitioners and leadership tools so they can better communicate their capacity needs as well as their successes.

At the intersection of policy steering in targeted domains and creating commonplace approaches in AWE practice, it is advantageous to utilize a solid conceptual framework to help identify some of the more fundamental capacity-building needs as they come to the fore, namely access to reliable infrastructure, data resources, and the professional development required to carry out the initiatives (McIntyre, 2008). Building capacity helps develop education systems and providers into more nimble conduits for the provision of flexible skills and competencies tailored to the demands, competitive pressures, and uncertainties of a rapidly changing economy (Campbell \& Love, 2016). Capacity building is an essential part of upgrading to a long-term perspective for shoring up educational systems to face the imminent transformations in society (Lauzon, 2013). AWE and CP initiatives cannot thrive in a strategic void. Merely mainstreaming standards, data requirements, and procedures will not necessarily equate to meaningful pedagogical implications for adult learner success, or automatically solve the issues of interoperability or sustainability. Creating interoperable systems and establishing common metrics may lead to compliance, but to achieve the kinds of systems integration and transformation that have been outlined, strategic capacity building and active participation are required at all levels. Viable educational reforms will need to go beyond topdown mandates. In order to succeed they will also require participation and meaningful capacity building (especially at local community and state levels). The WIOA and the CP model make the most sense when they are embedded within a participatory and capacity building framework, where the systems feedback loops built into the 
policy design are cooperative and active, enabling an dynamic practice-to-policy movement of knowledge back into the designed system.

WIOA has embarked on an ambitious mission to define transecting sets of adult learning competencies and workforce skills applicable in adjoining sectors. These efforts aim to promote a convergence in standards and expectations in adult and postsecondary learning, with an intent of increased cross-recognition of degrees and credentials. However, the desired AWE parity and coordination may not emerge without implementation guidance and continued capacity building. The initiatives require a coherent framework and improved policy incentives, more robust policy scaffolding, and attention to adequate capacity building for implementation.

Unfortunately, it cannot be assumed that capacity building efforts will be initiated at the higher levels of governance. Local leadership and program providers can use the conceptual framework to develop language and make arguments for the necessary capacity building, professional development, and streamlining of resources. Engaging in such a process at the local level, utilizing a capacity-building framework, helps create a reverse path for the mainstreaming of successful AWE and CP initiatives. When successful programs are designed and built locally-for example Washington state's I-BEST or Minnesota's Fast TRAC initiatives-they can then influence other state and eventually federal-level policies, ultimately improving the national uptake of effective programming (practice-to-policy). In developing local capacity and promoting this policy feedback-loop-which is activated by reinforcing the interdependencies between consortia, partnerships, and networks-local and regional level stakeholders can participate in purposefully building the needed capacity to improve the implementation and sustainability of AWE and CP initiatives. Practitioners need the necessary tools to increase the flow of information from practice back up to policy. 


\section{References}

Alamprese, J. (2016). Building career pathways systems for education, training, and employment. Bethesda, MD: Manhattan Strategy Group.

Alamprese, J.A., \& Lymardo, C. (2012). Policy to performance toolkit: Transitioning adults to opportunity. U.S. Department of Education, Office of Vocational and Adult Education. Retrieved from: http://lincs.ed.gov/lincs/resourcecollections/ careerpathways/profile_50

Brown, E., \& Holcomb, P. (2018, April). An institutional analysis of American Job Centers: Key institutional features of American Job Centers. Mathmatica Policy Research, on behalf of the US Department of Labor. Retrieved from https://wdr.doleta.gov/research/ FullText_Documents/ETAOP_2018-03_KeyFeatures_ AJCs_508_Compliant.pdf

Campbell, C., Love, I., \& Education Commission of the States. (2016). Leveraging community colleges in the Workforce Innovation and Opportunity Act: A blueprint for state policymakers. State-Federal Partnerships in Postsecondary Education. Education Commission of the States.

Ceballos, R. M. (2006). Adult education for community empowerment: toward the possibility of another world. In S.B. Merriam, B.C. Courtenay, \& R.M. Cervero (Eds.), Global Issues and Adult Education (pp. 319331). San Francisco, CA: Josey Bass.

Cincinnato, S., De Wever, B., Van Keer, H., \& Valcke, M. (2016). The influence of social background on participation in adult education: Applying the cultural capital framework. Adult Education Quarterly: A Journal of Research and Theory, 66(2), 143-168. doi:10.1177/0741713615626714

Couch, K. A., Ross, M. B., \& Vavrek, J. (2018). Career Pathways and integrated instruction: A national program review of I-BEST implementations. Journal of Labor Research, 39(1), 99-125.

Council for Adult and Experiential Learning. (2008). Adult learning in focus: National and state-by-state data. Chicago, IL: Author.
Cushing, E., Therriault, S., \& English, D. (2017, November). Developing a college- and career-ready workforce an analysis of ESSA, Perkins, and WIOA. American Institutes of Research, College \& Career $\&$ Readiness \& Success Center. Retrieved from https://ccrscenter.org/sites/default/files/CareerReadyWorkforce_Brief_Workbook.pdf

Foman, S. G., Shapiro, E. S., Codding, R. S., Gonzales, J. E., Reddy, L. A. Rosenfield, S. A., Sanetti, L. M. H., \& Stoiber, K. C. (2013). Implementation science and school psychology. School Psychology Quarterly, 28(2), 77-100. doi: 10.1037/spq0000019

Hoogervorst, J. J. (2011). A framework for enterprise engineering. International Journal of Internet \& Enterprise Management, 7(1), 5-40.

Horner, R. H., Sugai, G., \& Fixsen, D. L (2017). Implementing effective educational practices at scales of social importance. Clinical Child \& Family Psychology Review, 20(1), 25-35.

Ladinsky, J. (2017). From WIA to WIOA: Lessons for the implementation of the Workforce Innovation and Opportunities Act. Journal of Rehabilitation Administration, 39(2), 107-117.

Lauzon, A. (2013). From agricultural extension to capacity development: exploring the foundations of an emergent form of practice. International Journal of Lifelong Education, 32(2), 247-266. doi:10.1080/02601370.201 2.736087

Mariotti, F. (2012). Exploring interorganizational learning: a review of the literature and future directions. Knowledge and Process Management, 19(4), 215-221.

McDonnell, R. P., \& Soricone, L. (2018). Integrated career pathways: Lessons from accelerating opportunity. Journal of Research \& Practice for Adult Literacy, Secondary \& Basic Education, 52-62.

McIntyre, J. (2008). Professional knowledge formation and organisational capacity-building in ACE: Lessons from the Victorian Research Circles. Australian Journal of Adult Learning, 48(2), 213-236. 
Morgan, P. (2006). The concept of capacity. Maastricht: European Centre for Policy Management.

Morgan, J. (2016). Participation, empowerment and capacity building: Exploring young people's perspectives on the services provided to them by a grassroots NGO in subSaharan Africa. Children and Youth Services Review, $65,175-182$.

Mortrude, J., (2017). Integrated education and training: A Career Pathways policy \& practice. Center for Postsecondary and Economic Success.

Nastasi, B. K., \& Hitchcock, J. H. (2016). Mixed methods research and culture-specific interventions: Program Design and evaluation. Thousand Oaks, CA: SAGE Publishing.

National Association for Developmental Education. (2017). Retrieved from https://thenade.org/Mission-Vision-andGoals

National Institute for Literacy. (2001). A national plan for research and development in adult education and literacy. Retrieved from https://lincs.ed.gov/ professional-development/publications

Plested, B.A., Edwards, R.W., \& Jumper-Thurman, P. (2006, April). Community readiness: A handbook for successful change. Fort Collins, CO: Tri-Ethnic Center for Prevention Research.

Prins, E., \& Clymer, C. (2018). Career pathways in Chicago, Houston, and Miami: Key features and support services among adult education providers. Journal of Research \& Practice for Adult Literacy, Secondary \& Basic Education, 28-51.

Roumell, E. A. (2017). Building community programming capacity. In L. G. Martin (Ed.), International Compendium of Adult \& Continuing Education (p. 57). Sterling, VA: Stylus Publications.

Roumell Erichsen, E. A. \& Salajan, F. D. (2014). A comparative analysis of e-learning policy formulation in the European Union and the United States: Discursive convergence and divergence. Comparative Education Review, 58(1), 135-165.
Roumell, E. A., Salajan, F. D., Todoran, C. (2020). A survey of U.S. education policy regarding the education of adults. Educational Policy, 34(5), 785-815. doi: $10.1177 / 0895904818802416$

Roumell, E. A., Todoran, C., \& Khodakarami, N. (2019). A framework for community capacity building: The role of assessment and evaluation. In L. H. Hill (Ed.), Assessment, Evaluation, and Accountability in Adult Education. Sterling, VA: Stylus.

Roumell, E. A., Salajan, F. D., \& Todoran, C. (2019). An analysis and illustration of U.S. adult and workforce education policy. Adult Education Quarterly, 69(4), 295-314.

Smith, T. J., Dillahunt-Aspillaga, C. J., Kenney, R. M. (2017). Implementation of customized employment provisions of the Workforce Innovation and Opportunity Act within vocational rehabilitation systems. Journal of Disability Policy Studies, 27(4), 195-202. doi: 10.1177/1044207316644412

Struyk, R. J., Damon, M., \& Haddaway, S. R. (2011). Evaluating capacity building for policy research organizations. American Journal of Evaluation, 32(1), 50-69. doi: 10.1177/1098214010378355

Texas Higher Education Coordinating Board. (2014). Higher education laws and rules. Retrieved from http:// www.thecb.state.tx.us/apps/Laws/default.cfm

United Nations Development Program. (2008). UNDP capacity assessment methodology users guide. Retrieved from http://www.undp.org/content/ dam/aplaws/publication/en/publications/capacitydevelopment/undp-capacity-assessment-methodology/ UNDP\%20Capacity $\% 20$ Assessment $\% 20$ Users $\% 20$ Guide.pdf

U.S. Department of Education (2011) Strategic plan for fiscal years 2011-2014. Retrieved from https://www2. ed.gov/about/reports/strat/plan2011-14/plan-2011.pdf

U.S. Department of Education, Office of Vocational and Adult Education. (2013). An American heritageFederal adult education: A legislative history 19642013. Washington, DC: Author. 
U.S. Department of Labor. (2012). Joint Letter. Retrieved from https://careerpathways.workforcegps.org/ resources/2016/04/27/12/12/Career_Pathways_Joint_ Letter_2012

U.S. Department of Labor. (2016). Joint Letter. Retrieved from https://careerpathways.workforcegps.org/ resources/2016/04/27/12/12/Career_Pathways_Joint_ Letter_2016

Uvin, J. E. (2018). Are we on the brink of something big? Reflections on the current and future state of Career Pathways policy and practice. Journal of Research \& Practice for Adult Literacy, Secondary \& Basic Education, 97-108.
Womack, P. (2018). An investigation of the planning, implementation, and assessment of the 2010-2011 Texas Success Initiatives in developmental education (Unpublished dissertation). Texas A\&M University, College Station, TX.

Workforce Investment Act, Pub. L. 105-220, 29 U.S.C. §2801. (1998). Retrieved from http://www.govtrack.us/ congress/bills/105/hr1385

Workforce Innovation and Opportunity Act, Public Law No: 113-128 (2014). Retrieved from https://www.congress. gov/bill/113th-congress/house-bill/803 